\title{
CONTAMINATION, RISK ASSESSMENT OF HEAVY METALS IN SURFACE SEDIMENTS FROM A MARICULTURE BAY IN SOUTH CHINA
}

\author{
SONG, Y. M. ${ }^{1}-$ WANG, C. ${ }^{2 \#}-$ LIU, S. ${ }^{1}-$ PAN, J. C. ${ }^{1}-$ WEI, Y. N. ${ }^{1}-$ GUO, P. R..$^{1 *}$ \\ ${ }^{1}$ Guangdong Provincial Key Laboratory of Emergency Test for Dangerous Chemicals, \\ Guangdong Engineering and Technology Research Center of Online Monitoring for Water \\ Environmental Pollution, Guangdong Institute of Analysis, Guangzhou 510070, China \\ ${ }^{2}$ School of Public Health, Sun Yat-Sen University, Guangzhou 510080, China \\ ${ }^{\#}$ Wang, $C$ is co-first author. \\ *Corresponding author \\ e-mail: guopengran@gmail.com \\ (Received 29 $9^{\text {th }}$ May 2019; accepted $10^{\text {th }}$ Oct 2019)
}

\begin{abstract}
In order to assess the contamination, ecological and biotoxicity risk of heavy metals $(\mathrm{Cd}, \mathrm{Cr}, \mathrm{Cu}, \mathrm{Ni}, \mathrm{Pb}$ and $\mathrm{Zn}$ ) in mariculture area of China, the total concentrations and speciation of metals were analysed in the sediments from a typical mariculture bay in 2011 and 2013. The results show that most heavy metal concentrations in 2013 were lower than those in 2011. The residual and sulfide-bound fractions were the primary fractions of heavy metals. The pollution can be described in all the sampling sites of heavy metals (except Cd) with moderate to a very high degree by geo-accumulation index (Igeo), enrichment factor (EF) and pollution load index (PLI). According to the risk assessment code (RAC), $\mathrm{Cd}, \mathrm{Ni}$ and $\mathrm{Pb}$ posed a medium to very high ecological risk. The sampling sites that exhibited the biotoxicity risk in 2013 had higher biotoxicity levels than that in 2011. Based on statistical analysis and environmental investigation, four sites (S1, S2, S4 and S7) were highly affected by the environmental pollutants which primarily resulted from the combustion of gasoline and diesel fuel and the ships protective layer.
\end{abstract}

Keywords: ecological risk, biotoxicity risk, Zhelin Bay, speciation, pollution load index, the risk assessment code

\section{Introduction}

Heavy metals in ecosystems have received extensive attention because they are toxic, non-biodegradable, and easily bioaccumulate in organisms (Al-Othman et al., 2012; Dabney et al., 2018; Gao et al., 2012; Ghosh et al., 2018; Islam et al., 2014; Väänänen et al., 2016; Yang et al., 2012). With rapid industrialization and economic development in the coastal region of South China, heavy metals from industrial waste, sewage runoff, and agricultural discharges, are continuously introduced into the estuarine and bay environment through rivers, runoff, dust deposition and land-based point sources (El Nemr et al., 2016; Hyun et al., 2007; Wu et al., 2015; Yu et al., 2008). Due to the adsorption, hydrolysis, and co-precipitation of heavy metals, most of such pollutants deposit in the sediments and only a small part of free metal ions leave in water (Chaudhary et al., 2015; Hu et al., 1997; Nobi et al., 2010; Zwolsman et al., 2013.)

In recent decades, various assessment indices have been applied to assess the environmental pollution and risk of heavy metals in marine sediments. The heavy metal contamination in sediments is evaluated by the geo-accumulation index (Igeo), enrichment factor (EF) and pollution load index (PLI) (Gu et al., 2018; Liu et al., 2014; Varol et al., 2011; Wang et al., 2016;). In particular, the Hakanson risk index is prevalent in evaluating the ecological risk posed by heavy metals in sediments (Wu et al., 2014; Yi 
et al., 2011; Zhuang et al., 2014.). However, the mobility and toxicity of heavy metals in sediment depend not only on their total concentrations, but also on their physicochemical fractions described as "speciation" (Yuan et al., 2004; Zhou et al., 2004.). The sequential extraction (SE) technique is often used to determine heavy metal speciation in sediments, defined operationally as acid soluble, reducible, oxidizable and residual fractions (Gao et al., 2010; Zhang et al., 2013.). Meanwhile, sediment quality guidelines (SQGs) and acid volatile sulfide (AVS)-simultaneous extracted metals (SEM) model are widely applied to analyze the bio-toxicity of heavy metals (Prica et al., 2008; Poot et al., 2009; Sundaray et al., 2011.). The exchangeable and carbonate fractions are usually used in the method of the risk assessment code (RAC) to assess the ecological risk.

Zhelin Bay, a semi-enclosed estuarial bay, which situated in the northeast part of Guangdong Province, is one of the most developed areas in China. Zhelin Bay is the largest cage mariculture areas and a vital culture fish zone in South China (Qiao et al., 2010) with many seaport container terminals for international seafood export. Due to the maritime activities, a lot of phosphorus, nitrogen, and organic wastes are discharged, and consequently result in water eutrophication (Cao et al., 2007; Liang et al., 2011; Wu et al., 2016; Xia et al., 2016). Meanwhile, the heavy metal pollution in the bay area is getting worse (Qiao et al., 2010; Xia et al., 2016). The high concentration of heavy metals in sediments can be directly or indirectly bio-accumulated in benthic invertebrates, as sediments provide the benthic fauna food sources and habitats. Therefore, the environmental hazards in the bay become increasingly severe (Kalantzi et al., 2013). The risk assessment of heavy metals in the sediment of the culture area has gained much attention because of the pollution characteristics and ecological hazards of heavy metals.

Our previous study suggested that the ecological risk level of heavy metals in this area is medium to high, especially at the northwest coastal area of the semi-closed bay (Wang et al., 2016). This study was conducted to consolidate and complement the previous results. PLI was used to assess the metal contamination compared with the EF and $I_{\text {geo }}$ results. Based on heavy metal speciation, RAC was used to assess the ecological risk, and the results were compared with the Hakanson risk index. The AVS-SEM model was used to predict the bio-toxicity risk, and the results were compared with the SQGs. The study aims to analyze and evaluate the pollution and risk of heavy metals in this area, and identify the potential sources of high risk. The results could provide crucial information for the monitoring, management and conservation of coastal environments.

\section{Materials and methods}

\section{Sampling}

Samples of surface sediment from eleven sites were collected using a Petersen grab in September 2011 and August 2013 (Fig. 1) from Zhelin Bay in southern China. Temperature, salinity, $\mathrm{pH}$ and dissolved oxygen of the bottom water were measured by YSI water quality sensors on site (600R mode, YSI Inc., USA). Triplicate sediment samples were placed in the $\mathrm{N}_{2}$ filled polypropylene bags rapidly after collection, immediately transported to the laboratory and freeze-dried before chemical analysis.

\section{Chemical analysis}

After drying at $70{ }^{\circ} \mathrm{C}$ for more than $24 \mathrm{~h}$, the samples were re-weighted for the determination of moisture. Sediment total organic carbon (TOC) contents were estimated 
by the wet oxidation method using $\mathrm{K}_{2} \mathrm{Cr}_{2} \mathrm{O}_{7}-\mathrm{H}_{2} \mathrm{SO}_{4}$ (Mingorance et al., 2007). The total concentration of heavy metal in sediment samples was analyzed following the EPA 3052 method (Wang et al., 2011). The concentrations of $\mathrm{Al}, \mathrm{Fe}, \mathrm{Mn}, \mathrm{Si}, \mathrm{Cu}, \mathrm{Ni}, \mathrm{Pb}, \mathrm{Zn}, \mathrm{Cr}$ and $\mathrm{Cd}$ in the final solutions were measured by microwave plasma-atomic emission spectroscopy (MP-AES, Agilent 4200) and atomic absorption spectrometry (AAS, Hitachi Z-2000). Analytical accuracy was achieved by the use of blanks and certified reference materials including GBW 07314 and GBW 07334, issued by the State Oceanographic Administration of China.

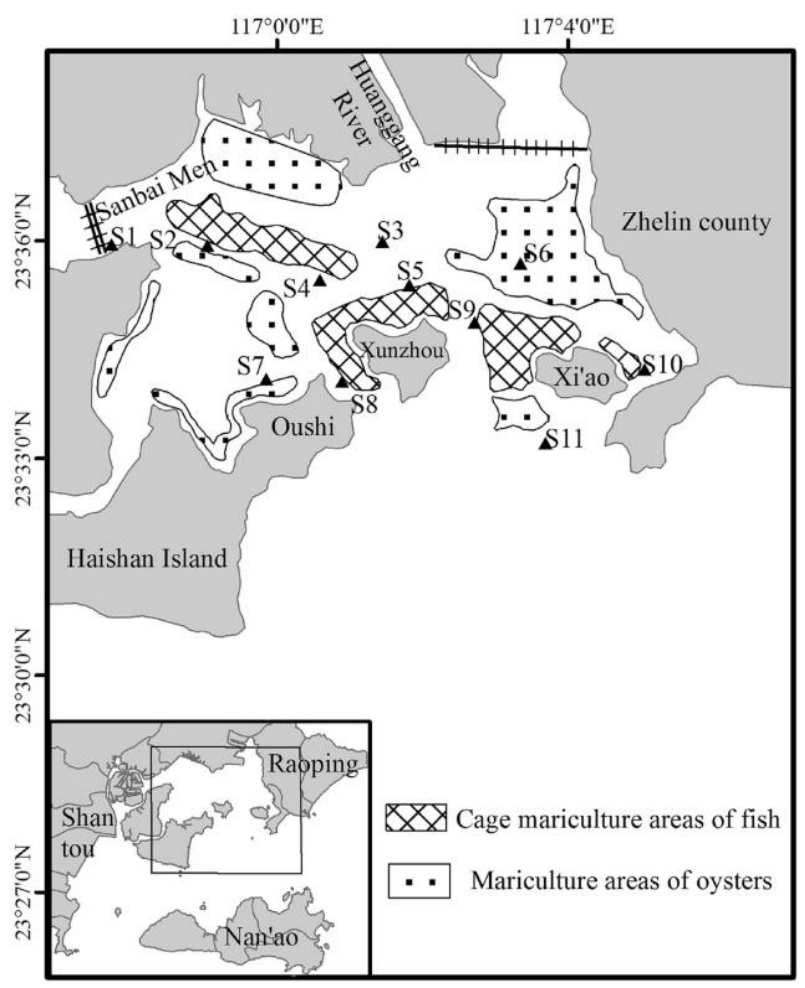

Figure 1. The study area and sediment sampling sites in Zhelin Bay along the southern coast of China

Extraction operations were performed by rotary shaking at $20^{\circ} \mathrm{C}$ in dark environment with $100 \mathrm{ml}$ of sealed centrifuge tubes. By centrifuging (4000 rpm, $10 \mathrm{~min}$ ), the separation of the solid from solution was carried out for each step. The supernatant was then thrown away, and the residual was rinsed and centrifuged again. The centrifuge tubs were filled with $\mathrm{N}_{2}$ in the experimental procedure. After acidifying the metal solutions with $\mathrm{HNO}_{3}$, the metal concentration was determined by MP-AES and graphite furnace atomic absorption spectrometry (GFAAS, Thermo SOlAAR M6).

Five fractions from $4.5 \mathrm{~g}$ wet sediment were extracted using the proposal sequential extraction (PSE) procedure (Wang et al., 2011; Xia et al., 2016). Five fractions were weak acid soluble fraction (F1: $\mathrm{pH} 5.0,1 \mathrm{M} \mathrm{NaOAc}$, sample dry weight/extractant volume (SE) 1:15, $5 \mathrm{~h}$ ), reducible fraction $\left(\mathrm{F} 2: \mathrm{pH} 2.0,0.2 \mathrm{M} \mathrm{NH}_{2} \mathrm{OH} \cdot \mathrm{HCl}+0.2 \mathrm{mM}\right.$ EDTA-Na2, SE 1:15, $5 \mathrm{~h}$ ), organic matter bound fraction (F3: $\mathrm{pH}$ 9.8, 0.1 $\mathrm{M} \mathrm{Na}_{4} \mathrm{P}_{2} \mathrm{O}_{7}, \mathrm{SE}$ 1:10, $5 \mathrm{~h}$ ),

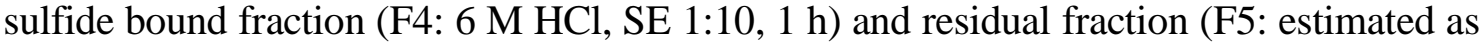
the total metal content). F1 was the bioavailable fraction of heavy metals including the exchangeable and carbonates bound fractions. 
The procedure for AVS analyses was protected by $\mathrm{N}_{2}$ and the same with that by Allen et al. (1993). The suspension in the acidified sediment was filtrated with a $0.45 \mu \mathrm{m}$ membrane filter (Fang et al., 2005) and analyzed by MP-AES and GFAAS. Standard materials validated the results. By methylene blue method, the sulfide in the trapping solution was analyzed.

Ultra-pure, deionized water (Milli-Q) was boiled and purged with nitrogen to remove dissolved oxygen. All glassware and plastic containers were soaked in $2.7 \mathrm{M} \mathrm{HNO}_{3}$ for at least $24 \mathrm{~h}$ and rinsed with deionized water before use. Standard solutions were prepared by dilution of $1000 \mu \mathrm{g} / \mathrm{mL}$ stock solutions with deionized water. All chemicals used in the experiment were at least of analytical reagent grade (p. A.) or superior purity. The concentrations of sediment components, including AVS, TOC, and metals were expressed as dry weight normalized concentrations.

\section{Assessment of the metal contamination}

The index of contamination factor (CF) and the pollution load index (PLI) were used to describe the sediment quality. PLI of the six metals were counted (Islam et al., 2015). The PLI was defined as the nth root of the multiplications of the CF of metals.

$$
\mathrm{PLI}=\left(C F_{1} \times C F_{2} \times C F_{3} \times \ldots \times C F_{n}\right)^{1 / n}
$$

where $C F_{\text {metals }}=C_{\text {metal }} / C_{\text {background }}$.

The background values of $\mathrm{Cd}, \mathrm{Cr}, \mathrm{Cu}, \mathrm{Ni}, \mathrm{Pb}$ and $\mathrm{Zn}$ in sediment were $0.15,28.6,15.8$, 14.8, 32.2 and $57.8 \mathrm{ug} / \mathrm{g}$, respectively (Qiao et al., 2009; Wang et al., 2010). PLI evaluated the overall contamination evaluation for all sites and a contribution consequence of the six metals. Therefore, the PLI value of zero indicated excellence, 1.0 represented only baseline level pollutants, and more than 1.0 indicated gradual deterioration of estuarine environment (Tomilson et al., 1980). The contamination factor (CF) of a given metal was calculated as the ratio of its measured concentration to natural abundance. The CF was then classified into four grades for monitoring the pollution from each metal over a period of time: low degree $(\mathrm{CF}<1)$, moderate degree $(1 \leq \mathrm{CF}<3)$, considerable degree $(3 \leq \mathrm{CF}<6)$, and very high degree $(\mathrm{CF} \geq 6)$. Thus, the $\mathrm{CF}$ values indicated the enrichment of each metal in sediments over a period of time (Islam et al., 2015).

\section{Assessment of risk}

\section{Assessment of ecological hazardous risk}

In order to assess the risk to the ecological environment, the RAC was applied (Perin et al., 1985; Zhao et al., 2012), which was defined as Equation 2:

$$
\mathrm{RAC}=\frac{[\mathrm{M}]_{\text {Weak }}}{[\mathrm{M}]_{\text {Total }}} \times 100 \%
$$

where $[\mathrm{M}]_{\text {Weak }}$ was the concentration of metals in weak acid soluble fraction, and $[\mathrm{M}]_{\text {Total }}$ was the total concentration of metals. According to the RAC values, each sample falled into one of the five tiers: i) $\mathrm{RAC} \leq 1 \%$ (no risk); ii) $1 \%<\mathrm{RAC} \leq 10 \%$ (low risk); iii) $10 \%<\mathrm{RAC} \leq 30 \%$ (medium risk); iv) $30 \%<\mathrm{RAC} \leq 50 \%$ (high risk); v) $50 \%<\mathrm{RAC}$ (very high risk). 


\section{Assessment of biotoxicity risk}

The concentrations of AVS, SEM and TOC were used to predict the toxicity (Di Toro et al., 2005). If ( $\sum$ SEM-AVS $) / f_{\text {OC }}$ was less than $150 \mu \mathrm{mol} / \mathrm{g}_{\mathrm{OC}}$, adverse effects due to SEM metals were not expected, and if ( $\sum$ SEM-AVS) $/ f_{\mathrm{OC}}$ was over than $3400 \mu \mathrm{mol} / \mathrm{g}_{\mathrm{OC}}$, suggested acute toxicity, and the range of uncertain effects was 150 $3400 \mu \mathrm{mol} / \mathrm{g}_{\mathrm{OC}}$ (McGrath et al., 2002).

\section{Quality control and data analysis}

The AVS, SEM and speciation analysis in replicates were measured to estimate the precision of the method. The relative standard deviation was less than $12 \%$ with the recoveries within $10 \%$ for the certified values. Total recoveries as the sum of individual metal fractions from SE compared to total contents were reasonable and ranged from 92.5-110\% for $\mathrm{Cd}, 90.0-112 \%$ for $\mathrm{Cu}, 93.4-110 \%$ for $\mathrm{Ni}, 90.5-108 \%$ for $\mathrm{Pb}$, and $96.9 \%$ $104 \%$ for $\mathrm{Zn}$, respectively.

In this work, factor analysis and correlation analysis were used to elucidate the relationship between metals, parameters and risks, characterize the associated components of heavy metals, and identify the sources of heavy metal contamination. Correlation analysis was performed with two-tailed Pearson test, with $\mathrm{p}<0.05$ and $\mathrm{p}<0.01$ as the significant values. The descriptive statistics were used by SPSS 19.0.

\section{Results and discussion}

\section{Distribution of heavy metals in the sediments}

Among all sampling sites, no fluctuation was observed in the values of $\mathrm{pH}$, dissolved oxygen (DO) and the moisture content of sediment (Table 1). However, the concentrations of $\mathrm{TOC}, \mathrm{Al}, \mathrm{Mn}, \mathrm{Fe}$, and $\mathrm{Si}$ show significant differences when comparing the values obtained in 2011 and 2013 ( $\mathrm{p}>0.05$ ). For instance, the average value of TOC, $\mathrm{Al}, \mathrm{Mn}, \mathrm{Fe}$, and $\mathrm{Si}$ was $1.11 \%, 9.86 \%, 0.104 \%, 5.09 \%$, and $22.27 \%$, respectively. In 2013, the average content of the above parameters reached $1.05 \%$, $10.17 \%, 0.104 \%, 5.07 \%$ and $22.84 \%$, respectively. The dissolved oxygen concentration was $2.88 \sim 4.72 \mathrm{mg} / \mathrm{L}$ in 2011 and $3.94 \sim 6.74 \mathrm{mg} / \mathrm{L}$ in 2013 , indicating that the sampling point was an anoxic area.

The mean concentration of each metal in 2013 was lower than that in 2011 (Fig. 2). In 2011 , the concentrations of $\mathrm{Cd}, \mathrm{Cr}, \mathrm{Cu}, \mathrm{Ni}, \mathrm{Pb}$ and $\mathrm{Zn}$ were in the ranges of $0.071-$ $0.150,27-35,26-45,31-204,6-83$ and $138-177 \mu \mathrm{g} / \mathrm{g}$, with the averages of $0.108,31$, $32,90,76$ and $156 \mu \mathrm{g} / \mathrm{g}$. In 2013 , the respective ranges were $0.057-0.110,21-30,23-$ $35,26-136,51-64$ and $116-196 \mu \mathrm{g} / \mathrm{g}$, with the averages of $0.082,26,28,55,56$ and $121 \mu \mathrm{g} / \mathrm{g}$. The average values of $\mathrm{Cu}, \mathrm{Ni}, \mathrm{Pb}$ and $\mathrm{Zn}$ were higher than their background values, and close to their background for $\mathrm{Cd}$ and $\mathrm{Cr}$. Heavy metal concentrations here generally exceeded the results from earlier studies (Qiao et al., 2010; Xia et al., 2016). There was a big difference on the distribution of $\mathrm{Cd}$ and $\mathrm{Ni}$ at those sampling sties. According to Figure $2 A$ and $C$, Cd was mainly distributed close to the land area (S1, S2, S5, S7 and S11), and Ni near the cage mariculture areas (S2, S4, S5, S8 and S10).

The speciation distribution of heavy metals in the mariculture sediment is shown in Figure 3. Cr fractions were not investigated because the valence state is more important than that its bound fraction. Cd mainly was found in F1 33.6 63.8\% in 2011 and 47.4 63.6\% in 2013 and F4 16.9 43.4\% in 2011 and 21.9 34.8\% in 2013. The dominant 
phase of $\mathrm{Cu}$ was in F5 53.6 69.2\% in 2011 and 51.4 69.0\% in 2013 and F4 20.0 32.7\% in 2011 and 18.9 29.1\% in 2013. Additionally, 5.3 12.2\% in 2011 and $6.4 \sim 14.4 \%$ in 2013 of total $\mathrm{Cu}$ concentration existed in F3. The dominant proportion $64.0 \sim 74.1 \%$ in 2011 and 58.7 67.4\% in 2011 of $\mathrm{Pb}$ was found in F5, and the proportions of other fractions were in the following order: F4 (12.8 19.5\%, 2011), (17.1 26.7\%, 2013); F1 (5.8 15.8\%, 2011), (7.2 17.4\%, 2013). The dominant phase of $\mathrm{Zn}$ was in F5, which accounted for 59.0 67.2\% in 2011 and 53.0 69.6\% in 2013. Ni was mostly retained in F5, representing 61.6 77.6\% (in 2011), 58.6 72.5\% (in 2013) of total concentration, and then F4 accounted for 8.9 23.6\% (in 2011), 13.2 18.3\% (in 2013) of total concentration. To sum up, $\mathrm{Cu}, \mathrm{Ni}, \mathrm{Pb}, \mathrm{Zn}$ from the sediment were mainly present in the residual fractions, followed by the sulfide bound fractions, and then the content of organic matter bound fractions in $\mathrm{Cu}$ was higher than that of $\mathrm{Cd}, \mathrm{Pb}, \mathrm{Ni}, \mathrm{Zn}$. The $\mathrm{Cd}$ in the sediments was dominated by sulfide and weak acid fractions, followed by the residual fractions. On the whole, the reducing fractions of five heavy metals were low.

\section{Assessment of the metal contamination}

Figure 4 shows the CF values of each heavy metal in 2011 and 2013. It was shown that most of the CF values of the heavy metals in 2013 were lower than that in 2011, and the concentrations of heavy metals varied significantly at the eleven sampling sites. According to the $\mathrm{CF}$ values of heavy metals, all sites for $\mathrm{Cd}$ were in low degree in both years. The most sites for $\mathrm{Cr}$ in 2013 were in low degree, but in moderate degree in 2011. All sites for $\mathrm{Cu}$ and $\mathrm{Pb}$ were in moderate degree. Zn (at S6 in 2011 and at S8 in 2013) were in considerable degree. Half of the sites for Ni (mainly near the cage mariculture areas) were in very high degree, and heavy metal in this figure were arranged by their pollution degrees, $\mathrm{Cd}<\mathrm{Cr}<\mathrm{Cu}<\mathrm{Pb}<\mathrm{Zn}<\mathrm{Ni}$. The pollution degrees assessed by $\mathrm{CF}$ were higher for $\mathrm{Zn}, \mathrm{Cu}, \mathrm{Cd}, \mathrm{Pb}, \mathrm{Ni}$ than that by $\mathrm{EF}$ and Igeo in our previous studies (Wang et al., 2016.), furthermore, there were unpolluted at all sites for $\mathrm{Cr}$ by EF and Igeo. In general, based on $\mathrm{CF}, \mathrm{EF}$ and $\mathrm{I}_{\mathrm{geo}}, \mathrm{Cd}$ at all sampling sites was unpolluted, and other heavy metals (except $\mathrm{Cr}$ ) at all sampling sites were polluted, especially $\mathrm{Ni}$ near the cage mariculture areas was polluted in high degree. The PLI values of each sampling site are shown in Figure 5. It was shown that the PLI values in 2013 were lower than that in 2011 at all sites (except S8). At S8, the CF values of $\mathrm{Cd}, \mathrm{Cu}, \mathrm{Zn}$ and $\mathrm{Ni}$ in 2013 were higher than that in 2011. In both of 2011 and 2013, the PLI values were over 1.0 at all sites, which indicated that this area was polluted. In this case, despite the comprehensive pollution decreases, heavy metal pollution (especially $\mathrm{Cd}, \mathrm{Cu}, \mathrm{Zn}$ and $\mathrm{Ni}$ ) at some site of this area should be considered for mariculture actions.

\section{Assessment of risk}

\section{Assessment of ecological risk}

The weak acid soluble fraction $(\mathrm{F} 1)$ of $\mathrm{Cd}, \mathrm{Cu}, \mathrm{Pb}, \mathrm{Zn}$ and $\mathrm{Ni}$ was analyzed, and the spatial distribution of calculated RAC values for those five metals in both two years was shown in Figure 6 by ArcGIS. The order of ecological risk assessed by RAC was: $\mathrm{Cd}>\mathrm{Ni}>\mathrm{Pb}>\mathrm{Cu}>\mathrm{Zn}$. The risk for heavy metals in 2013 was higher than that in 2011 (except $\mathrm{Cu}$ ), the inconsistency of ecological risk and contamination shown that ecological hazardous risk was heavily affected by bound fractions of heavy metals than by their total concentrations. 
The range of RAC values for $\mathrm{Cd}$ was from $33.6 \%$ to $68.7 \%$, which indicated high to very high risk. In 2011, very high risks for $\mathrm{Cd}$ were found at more than $50 \%$ of sites, especially at S5 and S9, where RAC values exceeded 60\%. In 2013, very high risks for $\mathrm{Cd}$ were found in most of the sites (especially at S3 and S8) except S7. The range of $\mathrm{RAC}$ values for $\mathrm{Ni}$ and $\mathrm{Pb}$ was from $5.0 \%$ to $17.8 \%$, from $5.80 \%$ to $17.4 \%$ respectively, which showed low to medium risk. For $\mathrm{Ni}$, the medium risks existed in more than half site in 2011 and more than 70\% sites in 2013, and a higher risk was found on S7 and S9 in 2011 and on S4 and S11 in 2013. For Pb, medium risks were contributed from less than half sites in both two years, and it presented higher risk at the S6 and S11 than other sites in 2011, S7 and S10 sites were higher in 2013. The range of RAC values for $\mathrm{Cu}$ and $\mathrm{Zn}$ were from $1.80 \%$ to $5.60 \%$, from $1.80 \%$ to $6.30 \%$ respectively, which indicated low risk. For $\mathrm{Cu}, \mathrm{S} 9$ and S10 showed higher risk than other sites in 2011, and S6 and S9 were higher in 2013. For Zn, S1 and S2 showed higher risk than other sites in 2011, and S1 and S10 were higher in 2013.

The order by Hakanson risk index was: $\mathrm{Cd}>\mathrm{Pb}>\mathrm{Ni}>\mathrm{Cu}>\mathrm{Zn}$ (Wang et al., 2016). The orders by both RAC and Hakanson risk index were approximately the same. However, assessed by Hakanson risk index, the risk degrees was a little lower than that by RAC, the higher risk occurred in 2011. Furthermore, the spatial distribution of ecological risk for each metal was different in two assessment methods.

\section{Assessment of biotoxicity risk}

The AVS and SEM concentrations of heavy metals in mariculture sediments were showed in Table 2. The AVS concentrations varied with sites, ranging from 0.005 to $2.012 \mu \mathrm{mol} / \mathrm{g}$ in 2011 and from 0.210 to $1.706 \mu \mathrm{mol} / \mathrm{g}$ in 2013. The average concentrations of $\mathrm{Cd}, \mathrm{Cu}, \mathrm{Ni}, \mathrm{Pb}$ and $\mathrm{Zn}$ were $0.0002,0.187,0.861,0.150$, $0.898 \mu \mathrm{mol} / \mathrm{g}$ in 2011, and 0.0003, 0.166, 0.602, 0.130, $0.992 \mu \mathrm{mol} / \mathrm{g}$ in 2013 respectively. The sums of AVS-SEM, $\sum$ SEM (SEM-Cd + SEM-Cu + SEM-Ni + SEM$\mathrm{Pb}+\mathrm{SEM}-\mathrm{Zn}$ ) at S2 and S8 in 2011 and at S2 and S5 in 2013 were higher than that on the other sampling sites.

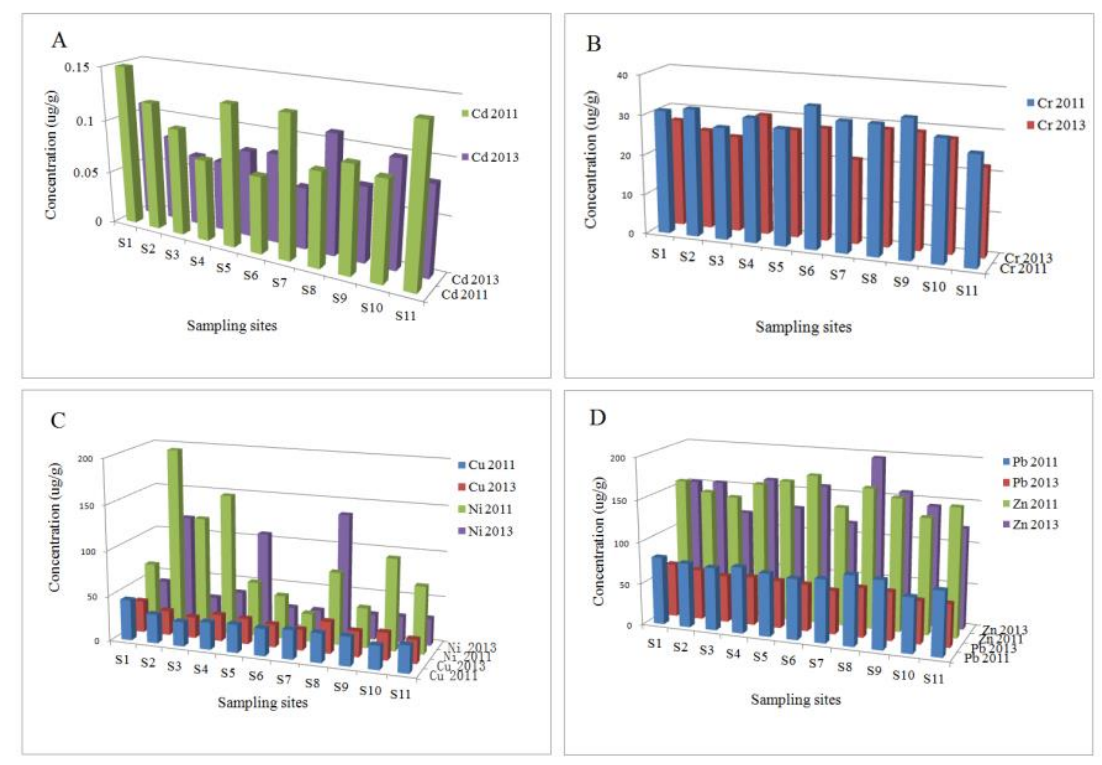

Figure 2. The total concentration distribution of each metal at sediment sampling sites in Zhelin Bay 

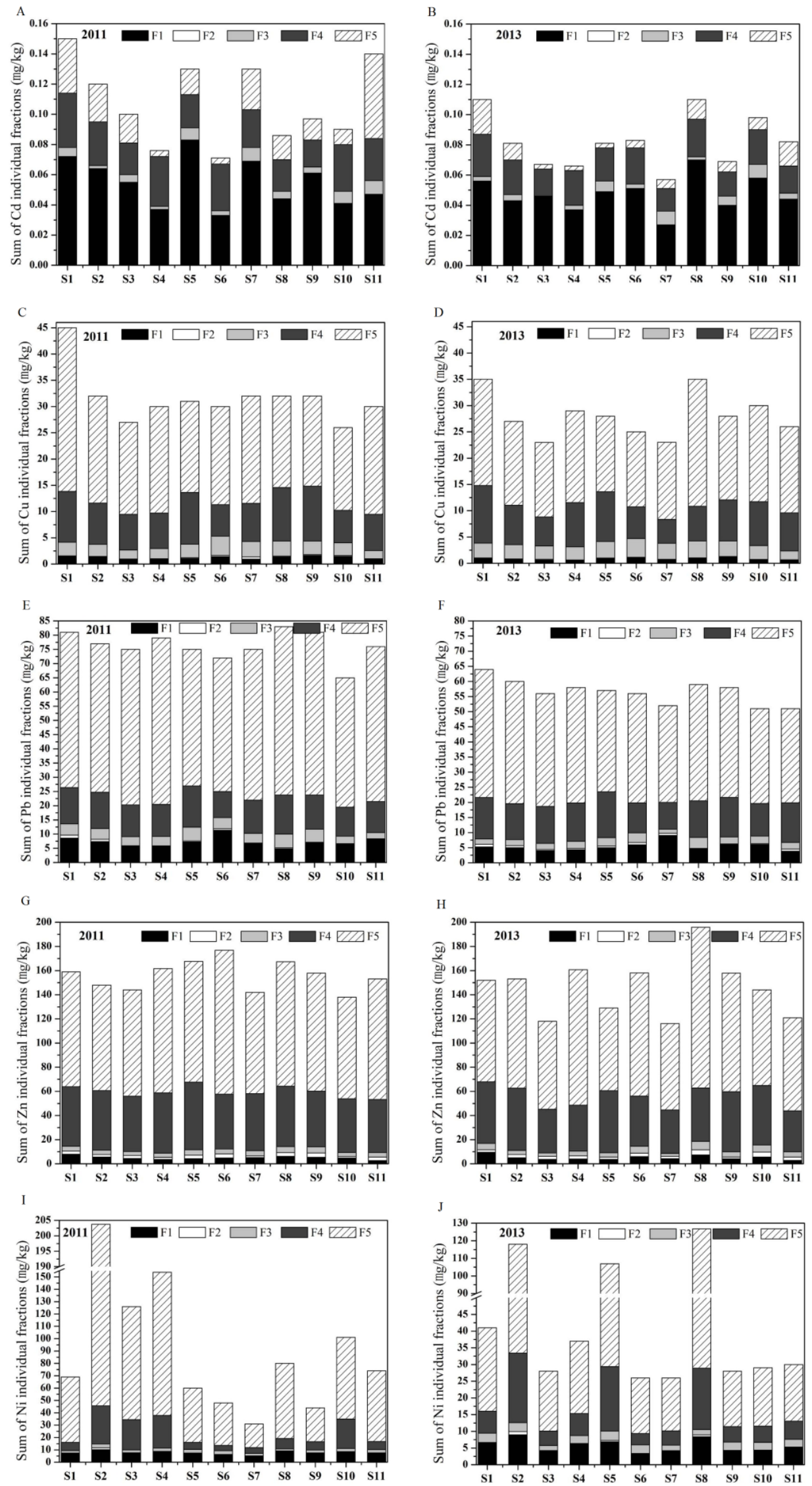

Figure 3. The speciation distribution of each metal at sediment sampling sites in Zhelin Bay 



Figure 4. The CF values of each heavy metal

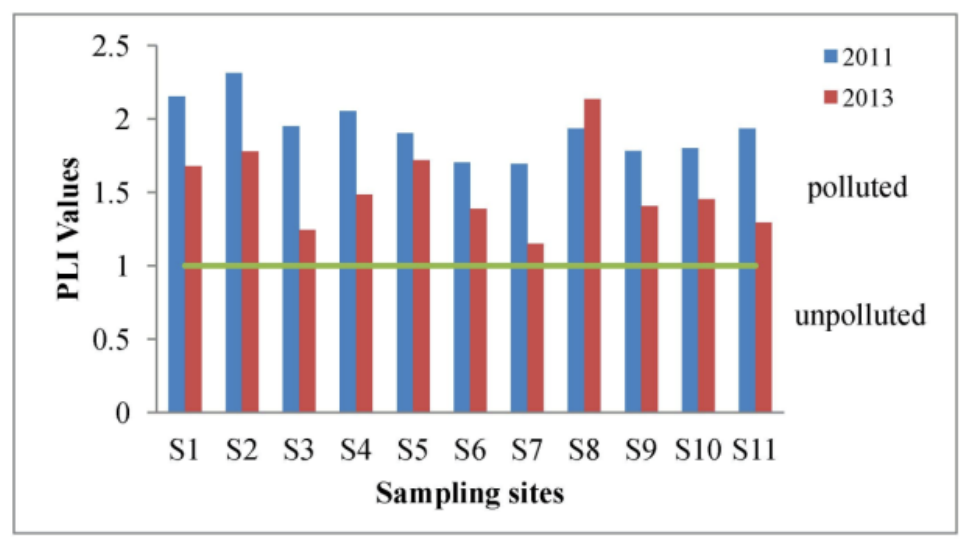

Figure 5. The PLI values of each sampling site 

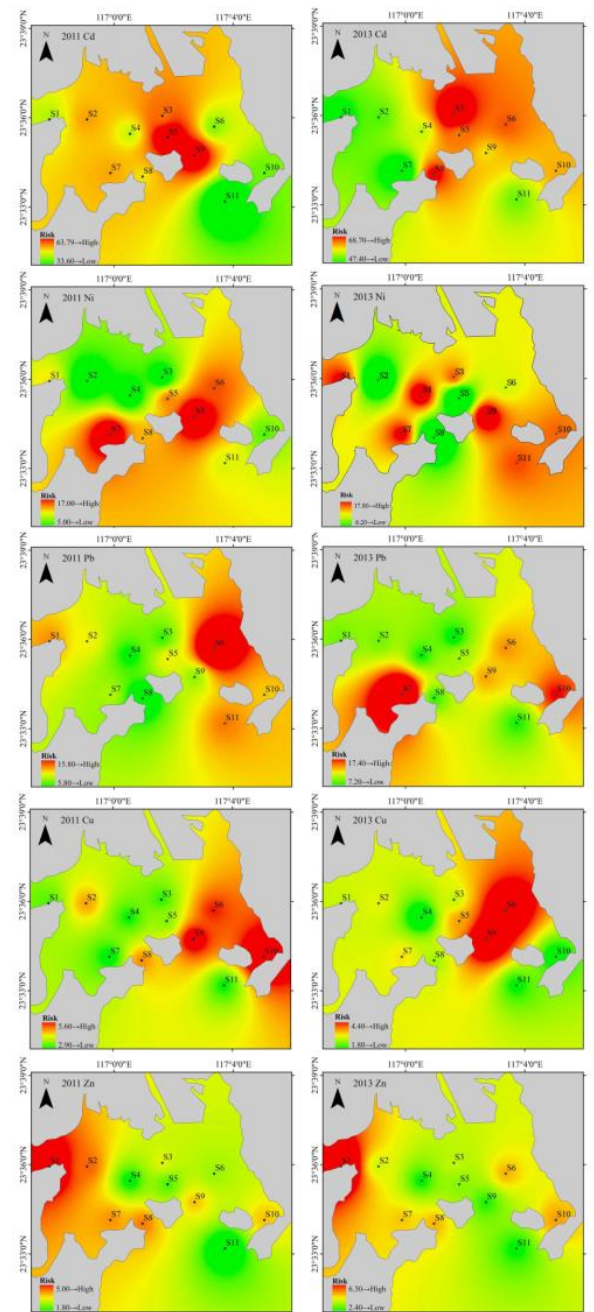

Figure 6. The ecological hazardous risk of heavy metals from Zhelin bay

Table 1. Characterization of sediment $(n=6)$ and water $(n=2)$ in sampling sites of the Zhelin Bay

\begin{tabular}{|c|c|c|c|c|c|c|c|c|c|c|c|c|c|c|c|c|}
\hline \multirow{3}{*}{ Site } & \multicolumn{12}{|c|}{ Sediment } & \multicolumn{4}{|c|}{ Water } \\
\hline & \multicolumn{2}{|c|}{ TOC (\%) } & \multicolumn{2}{|c|}{ SMC (\%) } & \multicolumn{2}{|c|}{$\mathrm{Al}(\%)$} & \multicolumn{2}{|c|}{$\operatorname{Mn}(\%)$} & \multicolumn{2}{|c|}{$\mathrm{Fe}(\%)$} & \multicolumn{2}{|c|}{$\mathrm{Si}(\%)$} & \multicolumn{2}{|c|}{ pH } & \multicolumn{2}{|c|}{ DO $(\mathrm{mg} / \mathrm{l})$} \\
\hline & 2011 & 2013 & 2011 & 2013 & 011 & 2013 & 011 & 2013 & 011 & 2013 & 011 & 2013 & 011 & 2013 & 2011 & 2013 \\
\hline $\mathrm{S} 1$ & 1.15 & & 61 & 4 & & & & 35 & & & 2.4 & 6 & 0 & 3 & 88 & .07 \\
\hline $\mathrm{S} 2$ & 1.04 & 1. & 50.0 & & 1 & & & 0.098 & 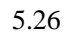 & & 22.6 & 22 & 36 & 49 & 31 & 4.01 \\
\hline S3 & 1.19 & 0 . & 47.9 & & & 10 & & 0.079 & & & 1 & & & & 97 & .02 \\
\hline $\mathrm{S} 4$ & 0.94 & 0.9 & 45.5 & 46.6 & 10.14 & 10.72 & 06 & 0.117 & 5.29 & 5. & 21.8 & 23.7 & 8.66 & 7.64 & 4.19 & 3.94 \\
\hline S5 & 1.12 & 1.2 & 43.5 & 47. & & 10.30 & 17 & 0.117 & 5. & & 21.5 & 23.5 & 8.70 & 7.77 & 4.72 & .92 \\
\hline S6 & 1.13 & 0. & 51 & 54 & & 10.13 & 06 & & & & 22.3 & & 8.30 & & 50 & 5.53 \\
\hline S7 & 1.10 & 0.7 & 48.6 & 50.6 & 10.23 & 9.68 & 087 & 0.090 & 5.18 & 4.56 & 22.7 & 22.4 & 8.70 & 7.86 & 4.10 & 6.74 \\
\hline S8 & 1.11 & 0.9 & 44.6 & & & & & & & & 22.6 & & & & 56 & 4.60 \\
\hline S9 & 1.15 & 1.1 & 47.0 & 51. & 9.5 & 10.24 & 17 & 0.121 &  & 5 & 21.5 & 23.2 & 8.78 & 7.74 & 3.45 & 4.66 \\
\hline S10 & 1.12 & 1.3 & 48.3 & 50.1 & 9.2 & 9.9 & 0.001 & 0.087 & & & 23.1 & 23.5 & 8.02 & 7.90 & 3.61 & 4.91 \\
\hline S11 & 1.12 & 1.1 & 52.7 & 53.0 & 9.52 & 9.7 & 0.125 & 0.098 & 5.03 & 4.90 & 22.4 & 23.4 & 8.30 & 7.80 & 3.60 & 5.83 \\
\hline Avg & 1.11 & 1.05 & 7.80 & 50.08 & 9.86 & 10.17 & 10 & 0.10 & & 5.07 & 22.27 & 22.84 & 44 & 7.69 & 3.78 & 4.84 \\
\hline $\mathrm{p}$ & \multicolumn{2}{|c|}{0.288} & \multicolumn{2}{|c|}{0.000} & \multicolumn{2}{|c|}{0.043} & \multicolumn{2}{|c|}{0.983} & \multicolumn{2}{|c|}{0.760} & \multicolumn{2}{|c|}{0.089} & \multicolumn{2}{|c|}{0.000} & \multicolumn{2}{|c|}{0.004} \\
\hline
\end{tabular}

AVS $=$ acid volatile sulfides; TOC $=$ total organic carbon; SMC $=$ sediment moisture contents; Avg: average

The data were statistical mean in the table; $\mathrm{p}<0.05$ : paired $\mathrm{t}$-test revealed that this difference was no significant 
Table 2. AVS and SEM concentrations of heavy metals in mariculture sediments in sampling sites of the Zhelin Bay (umol/g)

\begin{tabular}{|c|c|c|c|c|c|c|c|c|c|c|c|c|c|c|}
\hline \multirow{2}{*}{ Sites } & \multicolumn{2}{|c|}{ AVS } & \multicolumn{2}{|c|}{ SEM-Cd } & \multicolumn{2}{|c|}{ SEM-Cu } & \multicolumn{2}{|c|}{ SEM-Ni } & \multicolumn{2}{|c|}{ SEM-Pb } & \multicolumn{2}{|c|}{ SEM-Zn } & \multicolumn{2}{|c|}{$\sum$ SEM } \\
\hline & 11 & 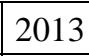 & 11 & 2013 & 2011 & 2013 & 011 & 2013 & 2011 & 2013 & 2011 & 2013 & 011 & 200 \\
\hline S1 & 212 & & & & & & & & & & & & & \\
\hline S & & & & & & & & & & & 88 & & 887 & \\
\hline S. & & & & & & & & & & & & & 20 & \\
\hline S & & & & & & & & & & & & & 36 & \\
\hline & & & & & & & & & & & & & 1 & \\
\hline S6 & & & & & & & & & & & & & 262 & \\
\hline & & & & & & & & & & & & & 1.338 & \\
\hline S8 & & & & & & & & & & & & & 99 & 20 \\
\hline & & & & & & & & & & & & & 2.118 & 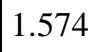 \\
\hline & .52 & & 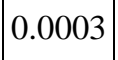 & & & & & & & & & & 2.472 & 2.00 \\
\hline 11 & 0.005 & 0.234 & 0002 & 0.0002 & 0.113 & 0.112 & 0.418 & 0.404 & 0.084 & 0.082 & 0.6 & 0.482 & 1.302 & 1.080 \\
\hline
\end{tabular}

$\sum \mathrm{SEM}=\mathrm{SEM}-\mathrm{Cd}+\mathrm{SEM}-\mathrm{Cu}+\mathrm{SEM}-\mathrm{Ni}+\mathrm{SEM}-\mathrm{Pb}+\mathrm{SEM}-\mathrm{Zn} ; f \mathrm{oc}=$ organic carbon fraction

The ratios of ( $\sum$ SEM-AVS $) / f_{\text {OC }}$ obtained in our study sites were calculated to 113 , $228,145,271,-2,111,66,115,81,174,116 \mu \mathrm{mol} / \mathrm{gOC}$ in 2011 , and 48, 243, 100, 136, 170, 97, 10, 167, 115, 63, $77 \mu \mathrm{mol} / \mathrm{g}$ OC in 2013, respectively (Fig. 7). The results indicated that there were no adverse effects, except S2, S4, and S10 in 2011, and except S2, S5 and S8 in 2013.



Figure 7. The ratios of $\left(\sum S E M-A V S\right) / f O C$

The results of no adverse effects by AVS-SEM were in accord with the prediction results by the mean ERL quotients (Wang et al., 2016), which indicated that the ratios of $\left(\sum \mathrm{SEM}-\mathrm{AVS}\right) / f_{\mathrm{OC}}$ could accurately be used to judge if there were no adverse effects and be of great help for environmental protection. Then, the uncertain risk part by AVS-SEM model could be compensated by other methods and would be discussed in the next step.

\section{Statistical analysis}

The average values of metal elements, characterization parameters and risk assessment values from 2011 to 2013 were analyzed by factor analysis and correlation 
analysis. Figure $8 \mathrm{~A}$ was factor loading plot to describe 20 features (six metals, seven characterization parameters and seven risk assessment indexes) from the different sampling sites. Figure $8 B$ was factor loading plot for the different sampling sites, each of which was described by 20 features. The correlation analysis was mainly carried out by 15 features (seven risk assessment indexes, six metals, and two characterization parameters), and the results were showed in Table 3.


Figure 8. The principal component analysis diagram for heavy metals and different sampling sites

Table 3. Correlation between the risk assessment indexes and the elements in the sediment of Zhelin Bay

\begin{tabular}{|c|c|c|c|c|c|c|c|c|c|c|c|c|c|c|c|}
\hline & Igeo & ef & PLI & RAC & ER & SQGs & $\begin{array}{l}\text { AVS- } \\
\text { SEM }\end{array}$ & Cd & $\mathrm{Cr}$ & $\mathrm{Cu}$ & $\mathrm{Ni}$ & $\mathbf{P b}$ & $\mathbf{Z n}$ & $\mathrm{Fe}$ & $\mathrm{Si}$ \\
\hline Igeo & 1 & $0.910^{* * *}$ & $0.998^{* *}$ & -0.394 & $0.923^{* *}$ & $0.856^{* * *}$ & $0.519^{*}$ & $0.455^{*}$ & 0.249 & $0.687^{*}$ & $0.733^{*}$ & $0.734^{*}$ & $0.567^{*}$ & $0.598^{*}$ & -0.355 \\
\hline ef & & 1 & $0.920^{* *}$ & $-0.523^{*}$ & $0.958^{* *}$ & $0.976^{* *}$ & $0.750^{*}$ & 0.265 & 0.180 & 0.396 & $0.933^{* *}$ & $0.516^{*}$ & $0.465^{*}$ & $0.524^{*}$ & -0.229 \\
\hline PLI & & & 1 & -0.426 & $0.936^{* *}$ & $0.871^{* *}$ & $0.537^{*}$ & $0.454^{*}$ & 0.221 & $0.675^{*}$ & $0.752^{*}$ & $0.733^{*}$ & $0.548^{*}$ & $0.590^{*}$ & -0.355 \\
\hline RAC & & & & 1 & $-0.487^{*}$ & -0.505 & $-0.502^{*}$ & -0.329 & 0.392 & -0.143 & $-0.52^{*}$ & -0.035 & 0.020 & -0.067 & -0.350 \\
\hline ER & & & & & 1 & $0.973^{* *}$ & $0.731^{*}$ & 0.224 & 0.144 & 0.418 & $0.902^{* *}$ & $0.672^{*}$ & 0.445 & $0.649^{*}$ & -0.361 \\
\hline SQGs & & & & & & 1 & $0.820^{* * *}$ & 0.133 & 0.139 & 0.269 & $0.975^{* *}$ & $0.501^{*}$ & 0.390 & $0.582^{*}$ & -0.259 \\
\hline $\begin{array}{c}\text { AVS- } \\
\text { SEM }\end{array}$ & & & & & & & 1 & -0.298 & 0.266 & -0.057 & $0.856^{* *}$ & 0.244 & 0.336 & $0.545^{*}$ & -0.052 \\
\hline $\mathrm{Cd}$ & & & & & & & & 1 & -0.397 & $0.662^{*}$ & 0.048 & 0.241 & -0.135 & -0.193 & 0.090 \\
\hline $\mathrm{Cr}$ & & & & & & & & & 1 & 0.314 & 0.047 & 0.360 & $0.819^{* *}$ & 0.454 & -0.383 \\
\hline $\mathrm{Cu}$ & & & & & & & & & & 1 & 0.078 & $0.703^{*}$ & $0.486^{*}$ & 0.209 & -0.214 \\
\hline $\mathrm{Ni}$ & & & & & & & & & & & 1 & 0.314 & 0.253 & $0.482^{*}$ & -0.147 \\
\hline $\mathrm{Pb}$ & & & & & & & & & & & & 1 & $0.571^{*}$ & $0.645^{*}$ & $-0.665^{*}$ \\
\hline $\mathrm{Zn}$ & & & & & & & & & & & & & 1 & $0.586^{*}$ & $-0.521^{*}$ \\
\hline $\mathrm{Fe}$ & & & & & & & & & & & & & & 1 & $-0.613^{*}$ \\
\hline $\mathrm{Si}$ & & & & & & & & & & & & & & & 1 \\
\hline
\end{tabular}

The determinant of coefficient is 0.000 ; *Correlation is significant at the level of $\mathrm{p}<0.05$; **Correlation is significant at the level of $\mathrm{p}<0.01$

In Figure $8 A$, the first factor described $41.76 \%$ of the common variance, and the second factor described $15.44 \%$. Rotation of the factor solution was necessary for better interpretation. The first factor was closely linked to $\mathrm{Cu}, \mathrm{Pb}, \mathrm{As}$ in Igeo, and the second factor was closely linked to Ni in AVS-SEM, SQGs, ER. These results indicated that 1) the ecological impacts of $\mathrm{Ni}$ were different from the impacts of $\mathrm{Cu}, \mathrm{Pb}, \mathrm{As} ; 2$ ) $\mathrm{Cu}$ and 
$\mathrm{Pb}$ were the major pollutants in the sediments; and 3) $\mathrm{Ni}$ was the main toxicity factor for ecological risk. From the correlation analysis, we concluded that: 1) the pollution factors ( $\mathrm{I}_{\text {geo }}$ and PLI) were significantly and positively correlated with Fe and all heavy metals except $\mathrm{Cr}$; 2) Ni was very significantly and positively correlated with SQGs, Hakanson risk index and AVS-SEM, followed by $\mathrm{Fe}$; 3) $\mathrm{Pb}$ was significantly and positively correlated with SQGs and Hakanson risk index; 4) $\mathrm{Si}$ was negatively correlated with most of the heavy metals, which showed that the metal pollutants were mostly from human activities.

The factor scores were used to analyze the contamination sources. In Figure $8 B$, the first factor for the common variance was $96.39 \%$ with high contribution from $\mathrm{S} 1$ and S7. The second described $2.70 \%$ and highly loaded by S2 and S4. Near to Sanbai Men port that was occupied in fishery and trade, the locations of the four sites were concentrated in the northwest coastal area of the semi-closed bay. It is evident that the wasters from the fishery, trade, port construction and other urban activities resulted in the serious environmental pollution. On the other hand, in the cage area for the fish and maricultrure, vessel activities were frequent, which suggested that the primary pollution sources were from the combustion of gasoline and diesel fuel (Zhu et al., 2016; Yuan et al., 2015).

\section{Conclusions}

In this study area, all the sampling sites were polluted by heavy metals $(\mathrm{Zn}, \mathrm{Cu}, \mathrm{Cr}$, $\mathrm{Pb}, \mathrm{Ni}$ ). The concentrations of heavy metals in 2013 were lower than that of 2011, and the residual fraction and sulfide bound fraction were the primary fractions of heavy metals. For each metal, Ni posed a moderate to very high risk; $\mathrm{Zn}$ and As posed a moderate to considerable risk; $\mathrm{Cr}, \mathrm{Cu}$ and $\mathrm{Pb}$ were at a moderate degree; $\mathrm{Cd}$ was unpolluted at the sampling sites. From the aspects of ecological risk, a medium to very high risk came from $\mathrm{Cd}, \mathrm{Ni}$ and $\mathrm{Pb}$. Except for the cage mariculture area (S2, S5 and S8), all the sites would be expected no biotoxicity. Through analyzing the various factors about the heavy metals, four sites (S1, S2, S4 and S7) were profoundly affected by the environmental pollutants which primarily resulted from the combustion of gasoline and diesel fuel and the ship protective layer. The intensive mariculture activity is one of the main reasons for the heavy metal pollution and ecological risk of sediments in Zhalin bay. The exploration of effective strategies is quite necessary in the future for keeping a good quality of the coastal environment and sustainable mariculture development.

Acknowledgments. The project was supported by GDAS'Special Project of Science and Technology Development (No. 2017GDASCX-0104), National Nature Science Foundation of China (21777150, 21307120), Science and Technology Planning Projects of Guangdong Province (2016B02024006, 2017A05040), Science and Technology Planning Projects of Guangzhou (201803030042).Sincere appreciation is expressed to Professor Hong Du from Shantou University for their sampling work and Professor Jingwei Xu from Changchun Institute of Applied Chemistry for language improvement. 


\section{REFERENCES}

[1] Al-Othman, Z. A., Ali, R., Al-Othman, A. M., Ali, J., Habila, M. A. (2012): Assessment of toxic metals in wheat crops grown on selected soils, irrigated by different water sources. - Arab. J. Chem. 9(S2): S1555-S1562.

[2] Allen, H. E., Fu, G., Deng, B. (1993): Analysis of acid-volatile sulfide (AVS) and simultaneously extracted metals (SEM) for the estimation of potential toxicity in aquatic sediments. - Environ. Toxicol. Chem. 12: 1441-1453.

[3] Chaudhary, M. Z., Ahmad, N., Mashiatullah, A., Ahmad, N., Ghaffar, A. (2013): Geochemical assessment of metal concentrations in sediment core of Korangi Creek along Karachi Coast, Pakistan. - Environ. Monit. Assess. 185(8): 6677-6691.

[4] Cao, L., Wang, W. M., Yang, Y., Yang, C. T., Yuan, Z. H., Xiong, S. B., Diana, J. (2007): Environmental impact of aquaculture and countermeasures to aquaculture pollution in China. - Environ. Sci. Pollut. R. 14(7): 452-462.

[5] Dabney, B. L., Clements, W. H., Williamson, J. L., Ranville, J. F. (2018): Influence of Metal Contamination and Sediment Deposition on Benthic Invertebrate Colonization at the North Fork Clear Creek Superfund Site, Colorado, USA. - Environ. Sci. Technol. 52(12): 7072-7080.

[6] Di Toro, D. M., McGrath, J. A., Hansen, D. J., Berry, W. J., Paquin, P. R., Mathew, R., Wu, K. B., Santore, R. C. (2005): Predicting sediment metal toxicity using a sediment biotic ligand model: methodology and initial application. - Environ. Toxicol. Chem. 24: 2410-2427.

[7] El Nemr, A., El-Said, G. F., Ragab, S., Khaled, A., El-Sikaily, A. (2016): The distribution, contamination and risk assessment of heavy metals in sediment and shellfish from the Red Sea coast, Egypt. - Chemosphere 165: 369-380.

[8] Fang, T., Li, X. D., Zhang, G. (2005): Acid volatile sulfide and simultaneously extracted metals in the sediment cores of the Pearl River Estuary, South China. - Ecotox. Environ. Saf. 61: 420-431.

[9] Gao, X. L., Chen, C. T. A. (2012): Heavy metal pollution status in surface sediments of the coastal Bohai Bay. - Water Res. 46: 1901-1911.

[10] Gao, X. L., Chen, C. T. A., Wang, G., Xue, Q. Z., Tang, C., Chen, S. Y. (2010): Environmental status of Daya Bay surface sediments inferred from a sequential extraction technique. - Estuar. Coast. Shelf Sci. 86: 369-378.

[11] Ghosh, S. P., Maiti, S. K. (2018): Evaluation of heavy metal contamination in roadside deposited sediments and road surface runoff: a case study. - Environ. Earth Sci. 77(7): 267.

[12] Gu, Y. G., Lin, Q., Jiang, S. J., Wang, Z. H. (2014): Metal pollution status in Zhelin Bay surface sediments inferred from a sequential extraction technique, South China Sea. Mar. Pollut. Bull. 81: 256-261.

[13] Hu, N. J., Huang, P., Zhang, H., Zhu, A. M., Liu, J. H., Zhang, J., He, L. H. (2015): Anthropogenic $\mathrm{Pb}$ input into Bohai Bay, China: evidence from stable $\mathrm{Pb}$ isotopic compositions in sediments. - Cont. Shelf. Res. 109: 188-197.

[14] Hyun, S., Lee, C. H., Lee, T., Choi, J. W. (2007): Anthropogenic contributions to heavy metal distributions in the surface sediments of Masan Bay, Korea. - Mar. Pollut. Bull. 54: 1059-1068.

[15] Islam, M. S., Han, S., Masunaga, S. (2014): Assessment of trace metal contamination in water and sediment of some rivers in Bangladesh. - J. Water Environ. Technol.12: 109121.

[16] Islam, M. S., Ahmed, M. K., Raknuzzaman, M., Habibullah-Al-Mamun, M., Islam, M. K. (2015): Heavy metal pollution in surface water and sediment: a preliminary assessment of an urban river in a developing country. - Ecol. Indic. 48: 285-291. 
[17] Kalantzi, I., Shimmield, T. M., Pergantis, S. A., Papageorgiou, N., Black, K. D., Karakassis, I. (2013): Heavy metals, trace elements and sediment geochemistry at four Mediterranean fish farms. - Sci. Total Environ. 444: 128-137.

[18] Liang, P., Shao, D. D., Wu, S. C., Shi, J. B., Sun, X. L., Wu, F. Y., Lo, S. C. L., Wang, W. X., Wong, M. H. (2011): The influence of mariculture on mercury distribution in sediments and fish around Hong Kong and adjacent mainland China wasters. Chemosphere 82(7): 1038-1043.

[19] Liu, J. J., Ni, Z. X., Diao, Z. H., Hu, Y. X., Xu, X. R.,(2018): Contamination level, chemical fraction and ecological risk of heavy metals in sediments from Daya Bay, South China Sea. - Mar. Pollut. Bull. 128: 132-139.

[20] McGrath, J. A., Paquin, P. R., Di, Toro, D. M. (2002): Use of the SEM and AVS Approach in Predicting Metal Toxicity in Sediments. - In: Fairbrother, A., Smolders, E. (eds,) Fact Sheet on Environmental Risk Assessment. International Council on Mining and Metals (ICMM), London, 10: 1-6.

[21] Mingorance, M. D., Barahona, E., Fernandez-Galvez, J. (2007): Guidelines for improving organic carbon recovery by the wet oxidation method. - Chemosphere 68(3): 409-413.

[22] Nobi, E. P., Dilipan, E., Thangaradjou, T., Sivakumar, K., Kannan, L. (2010): Geochemical and geo-statistical assessment of heavy metal concentration in the sediments of different coastal ecosystems of Andaman Islands, India. - Estuar. Coast. Shelf Sci. 87(2): 253-264.

[23] Perin, G., Craboledda, L., Lucchese, L., Cirillo, R., Dotta, L., Orio, A. A. (1985): Heavy Metal Speciation in the Sediments of Northern Adriatic Sea. A New Approach for Environmental Toxicity Determination. - In: Lekkas, T. D. (ed.) Heavy Metal in the Environment. CEP Consultant, Edinburgh, 2: 454-456.

[24] Poot, A., Meerman, E., Gillissen, F., Koelmans, A. A. (2009): A kinetic approach to evaluate the associated to acid volatile sulfide and simultaneously extracted metals in aquatic sediments. - Environ. Toxicol. Chem. 28: 711-717.

[25] Prica, M., Dalmacija, B., Roncevic, S., Krcmar, D., Becelic, M. (2008): A comparison of sediment quality results with acid volatile sulfide (AVS) and simultaneously extracted metals (SEM) ratio in Vojvodina (Serbia) sediments. - Sci. Total Env. 389(2-3): 235.

[26] Qiao, Y. M., Huang, C. J., Yang, Y. (2009): A preliminary study of heavy metal background values in Zhelin Bay of eastern Guangdong Province. - J. Trop. Oceanogr. 28(2): 81-85 (in Chinese).

[27] Qiao, Y. M., Huang, C. J., Zhao, J. G. (2010): Heavy metal accumulation and environmental quality assessment for surface sediment in Zhelin Bay. - Environ. Sci. 29(3): 325-327 (in Chinese).

[28] Sundaray, S. K., Nayak, B. B., Lin, S., Bhatta, D. (2011): Geochemical speciation and risk assessment of heavy metals in the river estuarine sediments - a case study: Mahanadi Basin, India. - J. Hazard. Mater. 186(2-3):1837-1846.

[29] Tomilson, D. C., Wilson, D. J., Harris, C. R., Jeffrey, D. W. (1980): Problem in assessment of heavy metals in estuaries and the formation of pollution index. - Helgol. Wiss. Meeresunlter. 33: 566-575.

[30] Väänänen, K., Kauppila, T., Mäkinen, J., Leppänen, M., Akkannen, J. (2016): Ecological risk assessment of boreal sediments affected by metal mining: Metal geochemistry, seasonality, and comparison of several risk assessment methods. - Integr. Environ. Assess. 12(4): 759-771.

[31] Varol, M. (2011): Assessment of heavy metal contamination in sediments of the Tigris River (Turkey) using pollution indices and multivariate statistical techniques. - J. Hazard. Mater. 195(1): 355-364.

[32] Wang, C., Du, H., Yang, Y. Y., Guo, P. R. (2011): Effect of sequential extraction for heavy metals speciation on mineral phases of sediment. - Chin. J. Anal. Chem.39: 18871892. 
[33] Wang, F., Huang, X. P., Zhang, J. P., Jiang, Z. J., Shi, Z. (2010): Distribution, accumulation and ecological risk of mercury in the sediment of the mariculture zone at Zhelin Bay of Guangdong province, Asian. - J. Ecotox. 5(2): 184-192 (in Chinese).

[34] Wang, Y., Wei, Y. N., Guo, P. R., Pan, J. C., Wu, Q. H., Liu, N. (2016): Distribution variation of heavy metals in maricultural sediments and their enrichment, ecological risk and possible source-A case study from Zhelin bay in Southern China. - Mar. Pollut. Bull. 113: 240-246.

[35] Wu, Q. H., Tam, N. F. Y., Leung, J. Y. S., Zhou, X. Z., Fu, J., Yao, B. (2014): Ecological risk and pollution history of heavy metals in Nanshan mangrove, South China. - Mar. Pollut. Bull. 104: 143-151.

[36] Wu, Q. H., Leung, J. Y. S., Geng, X. H., Chen, S. J., Huang, X. X., Li, H. Y., Huang, Z. Y., Zhu, L. B., Chen, J. H., Lu, Y. Y. (2015): Heavy metal contamination of soil and water in the vicinity of an abandoned e-waste recycling site: implications for dissemination of heavy metals. - Sci. Total Environ. 506-507(15): 217-225.

[37] Wu, R. S. S., Lam, K. S., Mackay, D. W., Lau, T. C., Yam, V. (1994): Impact of marine fish farming on water quality and bottom sediment a case study in the sub-tropical environment. - Mar. Environ. Res. 38(2): 115-145.

[38] Xia, B., Guo, P. R., Lei, Y. Q., Zhang, T., Qiu, R. L., Knorr, K. H. (2016): Investigating speciation and toxicity of heavy metals in anoxic-marine sediments - a case study from a mariculture bay in Southern China. - J. Soil Sediment. 16(2): 665-676.

[39] Yang, Y. Q., Chen, F. R., Zhang, L., Liu, J. S., Wu, S. J., Kang, M. L. (2012): Comprehensive assessment of heavy metal contamination in sediment of the Pearl River Estuary and adjacent shelf . - Mar. Pollut. Bull. 64(9): 1947-1955.

[40] Yi, Y. J., Yang, Z. F., Zhang, S. H. (2011): Ecological risk assessment of heavy metals in sediment and human health risk assessment of heavy metals in fishes in the middle and lower reaches of the Yangtze River basin. - Environ. Pollut. 159(10): 2575-2585.

[41] Yu, R., Yuan, X., Zhao, Y., Hu, G., Tu, X. (2008): Heavy metal pollution in intertidal sediments from Quanzhou Bay, China. - J. Environ. Sci. 20: 664-669.

[42] Yuan, C. G., Shi, J. B., He, B., Liu, J. F., Liang, L. N., Jiang, G. B. (2004): Speciation of heavy metals in marine sediments from the East China Sea by ICP-MS with sequential extraction. - Environ. Int. 30: 769-783.

[43] Yuan, G. M., He, G. F. (2015): Distribution and environmental geochemistry characteristics of heavy metals in surface sediment from Zhelin Bay to Dacheng Bay, Guangdong Province, China. - Earth and Environment 43(2): 190-197 (in Chinese).

[44] Zhang, R., Zhou, L., Zhang, F., Ding, Y., Gao, J., Chen, J., Yan, H., Shao, W. (2013): Heavy metal pollution and assessment in the tidal flat sediments of Haizhou Bay, China. - Mar. Pollut. Bull. 74: 403-412.

[45] Zhao, S., Feng, C. H., Yang, Y. R., Niu, J. F., Shen, Z. Y. (2012): Risk assessment of sedimentary metals in the Yangtze Estuary: new evidence of the relationships between two typical index methods. - J. Hazard. Mater. 241-242(4): 164-172.

[46] Zhou, Q. X., Kong, F. X., Zhu, L. (2004): Ecotoxicology: Principle and Methods. Science Press, Beijing.

[47] Zhu, Z. M., Xue, J. H., Deng, Y. Z., Chen, L., Liu, J. F. (2016): Trace metal contamination in surface sediments of intertidal zone from Qinhuangdao, China, revealed by geochemical and magnetic approaches: distribution, sources, and health risk assessment. - Mar. Pollut. Bull. 105(1): 422-429.

[48] Zhuang, W., Gao, X. L. (2014): Integrated assessment of heavy metal pollution in the surface sediments of the Laizhou Bay and the coastal waters of the Zhangzi Island, China: comparison among typical marine sediment quality indices. - PLoS One 9(4): e4145.

[49] Zwolsman, J. J. G., Van Eck, B. T. M., Der Weijden, C. H. (1997): Geochemistry of dissolved trace metals (cadmium, copper, zinc) in the Scheldt estuary, southwestern Netherlands: impact of seasonal variability. - Geochim. Cosmochim. Ac. 61(8): 16351652. 